\title{
Las paradojas del trabajo actoral en teatro independiente. Un estudio comparativo de las representaciones sociales sobre teatro independiente de actores y actrices de La Plata entre los orígenes y la actualidad
}

The paradoxes of acting work in independent theater. A comparative study of the independent theater representations of actors and actresses of La Plata between origins and today

\author{
Juliana Díaz \\ CONICET / UNLP, Argentina
}

RESUMEN El objetivo del artículo es indagar las rupturas y continuidades de la definición de teatro independiente en sus orígenes (primeras décadas del siglo pasado) en Buenos Aires y particularmente en la ciudad de La Plata, respecto a las representaciones más recientes que formula el colectivo de actores y actrices de teatro independiente en la ciudad. En este artículo, comprendemos a las representaciones sociales como modos de significar las interpretaciones que los sujetos hacen de su entorno y a partir de las cuales logran comunicarse (Castorina et al., 2010). Este concepto se explica en vinculación con la estructura social y los habitus del campo incorporados (Bourdieu, 2007) y se caracterizan por ser sistemas indeterminados y abiertos (Longo, 2004). En relación con el mundo del trabajo, las representaciones sociales son "objeto de luchas tanto colectivas entre grupos sociales, como individuales entre atribuciones y apropiaciones de clasificaciones por parte del sujeto" (Longo, 2004, p. 5).

Para ello, hemos llevado a cabo un análisis documental de distintos/as autores/as que han abordado los orígenes del teatro independiente en Buenos Aires como en La Plata. Además, realizamos veinte entrevistas en profundidad a actores y actrices residentes en la ciudad de La Plata, observaciones participantes en charlas, asambleas y reuniones que agrupan a distintos actores y actrices de teatro independiente y el proceso de ensayos y funciones de dos elencos del circuito independiente en La Plata. También, realizamos un total de ochenta y nueve encuestas de manera virtual dirigida a actores y actrices de la misma 
ciudad. Para su análisis, hemos puesto en diálogo los datos construidos desde una perspectiva cualitativa a partir de técnicas e instrumentos propios de la metodología cualitativa como cuantitativa. Para el procesamiento de datos, se han utilizado los softwares Statistical Package for the Social Sciences (SPSS) y Atlas/ti.

PALABRAS CLAVE Teatro independiente; trabajo; representaciones sociales.

ABSTRACT The objective of the article is to investigate the ruptures and continuities of the definition of independent theater in its origins (first decades of the last century) in Buenos Aires and particularly in the city of La Plata, in respect of the most recent representations formulated by the group of actors and independent theater actresses in the city. In this article, social representations are understood as ways to signify the interpretations that subjects make of their environment and from which they manage to communicate (Castorina et al., 2010). This concept is explained in connection with the social structure and the built-in habitus of the countryside (Bourdieu, 2007) and they are characterized by being indeterminate and open systems (Longo, 2004). In relation to the world of work, social representations are "the object of both collective struggles between social groups and individual struggles between attributions and appropriations of classifications by the subject" (Longo, 2004, p. 5).

To undertake this study, it has been carried out a documentary analysis of different authors who have addressed the origins of independent theater in Buenos Aires and La Plata. In addition, twenty in-depth interviews with actors and actresses residing in the city of La Plata, participant observations in talks, assemblies and meetings that bring together different actors and actresses from independent theater and the process of rehearsals and performances of two independent theater casts in La Plata were conducted, as well as a total of eighty-nine surveys in a virtual way aimed at actors and actresses from the same city. For the analysis, data constructed from a qualitative perspective using techniques and instruments typical of qualitative and quantitative methodology have been included. For data processing, the Statistical Package for the Social Sciences (SPSS) and Atlas/ ti software have been used.

KEYWORDS Independent theater; work; social representations. 
(...) yo mantengo que una obra de arte digna de este nombre y hecha a conciencia no es valorable, carece de valor comercial, no puede pagarse con dinero. Conclusión ji el artista no tiene rentas, tiene que morirse de hambre! (...) Somos obreros de lujo; pero resulta que nadie es lo bastante rico para pagarnos. Flaubert, carta a Geroge Sand (1872).

\section{Introducción}

El objetivo del artículo es indagar las rupturas y continuidades de la definición de teatro independiente en sus orígenes (primeras décadas del siglo pasado) en Buenos Aires y particularmente en la ciudad de La Plata, respecto a las representaciones sociales más recientes que formula el colectivo de actores y actrices de teatro independiente en la ciudad. En este artículo, comprendemos a las representaciones sociales como modos de significar las interpretaciones que los sujetos hacen de su entorno y a partir de las cuales logran comunicarse (Castorina et al., 2010). Este concepto se explica en vinculación con la estructura social y los habitus del campo incorporados (Bourdieu, 2007) y se caracterizan por ser sistemas indeterminados y abiertos (Longo, 2004). En relación con el mundo del trabajo, las representaciones sociales son "objeto de luchas tanto colectivas entre grupos sociales, como individuales entre atribuciones y apropiaciones de clasificaciones por parte del sujeto" (Longo, 2004, p. 5).

Para cumplir con los objetivos propuestos, hemos llevado a cabo un análisis documental de distintos/as autores/as que han abordado la temática a principios del siglo XX como Pelletieri (2006), González Velasco (2012), Mauro (2018, 2018a, 2018b) y Fukelman (2015, 2016, 2017, 2017a, 2017b)ํ. Además, hemos recuperado algunos aportes de Di Sarli (2014) y Radice y Di Sarli (2010) para especificar el caso en la ciudad de La Plata desde su etapa fundacional.

También, hemos analizado veinte entrevistas en profundidad a actores y actrices de la ciudad de La Plata entre los años 2017 y 2018. La selección de la muestra fue teórica con el fin de asegurar heterogeneidad en géneros, edades, formación artística y experiencias de la práctica (es decir, se han contemplado casos que trabajan obras de teatro para adultos/as, para niños/as, espectáculos de improvisación, teatro de máscaras, teatro danzado, entre otros).

1. En este trabajo somos conscientes de las diversas lecturas e interpretaciones que hacen los/as autores/as citados/as. Sin embargo, creemos que los trabajos en su diversidad pueden complementarse en tanto información histórica conjunta y en diálogo constante. 
Además, realizamos ochenta y nueve encuestas a actores y actrices de la ciudad de La Plata. Las encuestas son de carácter no probabilístico ${ }^{2}$ ya que no existen, hasta el día de la fecha, datos certeros de cuál es la población total de actores y actrices en la región. Asimismo, el objetivo de la implementación de esta técnica no es generalizar resultados estadísticos sino indagar, en diálogo con las otras técnicas, qué significados se otorgan al teatro independiente en el espacio local. Las encuestas fueron auto-administradas por web (López-Roldán y Fachelli, 2015, p. 15), es decir, que ha sido elaborada por el formulario de Google Docs y distribuida por redes sociales como Facebook, Instagram, Gmail y WhatsApp, con un gran aporte de la comunidad teatrera platense para su difusión. Finalmente, hemos realizado observaciones participantes en 2018 al trabajo de ensayos y funciones de dos elencos de La Plata, además de observar charlas, asambleas y reuniones que agrupan a distintos actores y actrices de teatro independiente en la ciudad entre el 2018 y 2019. Para el procesamiento de datos, se han utilizado los softwares Statistical Package for the Social Sciences (SPSS) y Atlas $/ \mathrm{ti}^{3}$.

Para su análisis, hemos puesto en diálogo los datos construidos desde una perspectiva cualitativa a partir de técnicas e instrumentos propios de la metodología cualitativa como cuantitativa. En este sentido, hemos indagado las representaciones encontradas en los distintos períodos para poder así determinar las rupturas y continuidades posibles de las representaciones sociales sobre teatro independiente.

\section{Sobre los orígenes del teatro independiente}

Salvando la diversidad de interpretaciones sobre el surgimiento y desarrollo del movimiento de teatro independiente en Buenos Aires, existe cierto consenso de ubicar su origen en las primeras décadas del siglo XX (precisamente entre los años '20 y '30). Si bien algunos/as autores/as como Pelletieri (2006) y Fukelman (2017b) han encontrado su origen junto con la fundación del Teatro del Pueblo ${ }^{4}$ encabezado por Leónidas Barletta, no se desconocen grupos anteriores surgidos en la década del '20. Incluso, ya para la fecha de 1927, años antes de la fundación del Teatro del Pueblo en Buenos Aires, se había anunciado públicamente el concepto de teatro independiente (Fukelman, 2016).

2. Es decir que no posee representatividad estadística, pero que cuenta con la ventaja de aplicar la técnica con escasos recursos económicos y humanos (Baranger, 2009).

3. El trabajo de campo ha sido elaborado en tiempos previos a la pandemia mundial. Por lo tanto, creemos que existe un gran desafío en estudios próximos respecto a indagar las representaciones de estos sujetos luego de la propagación del virus Covid-19. Esto es así considerando los efectos del virus que posiblemente han alterado nuestras vidas cotidianas (incluidas las experiencias laborales de actores y actrices de teatro independiente).

4. El acta fundacional del Teatro del Pueblo fue firmada en el año 1931 (Fukelman, 2016). 
Autoras como Mauro (2018), asocian sus orígenes en tiempos contemporáneos a las luchas organizadas a partir de la conformación de la Asociación Argentina de Actores en 1919 (Klein, 1988). De hecho, González Velasco (2012) realiza una síntesis muy completa sobre el modo en que los actores y las actrices fueron intentando alejarse del sector empresarial, buscando estrategias de producción autogestivas que, precisamente, lograran independizarlos/as. Según la autora, el objetivo de la autogestión era demostrar la inutilidad del sector empresarial en tanto intermediario productivo. En ese sentido, se asumía que el único interés del sector empresarial era la ganancia económica a costa de la explotación de los/as trabajadores/as de la actuación. Algunas de las demandas que motivaron la huelga fueron: descanso semanal, límites en los horarios de ensayos, regulación de los contratos, licencias por maternidad y accidentes, entre otras.

En este contexto, surgieron debates artísticos y políticos que, en cierto aspecto, resultaron como antecedentes a la conformación del teatro independiente (Fukelman, 2017a): las disputas entre el Grupo Boedo (que buscaba un arte para la revolución como vanguardia política donde el arte es un mediador para la organización obrera) y el Grupo Florida (considerado como una vanguardia estética que, a diferencia del otro grupo, buscaba una revolución para el arte). De todas formas, estas posturas tampoco eran determinantes porque, tal como menciona la autora, Leónidas Barletta perteneció al Grupo Boedo, aunque en su ejercicio dentro del Teatro del Pueblo propuso un nuevo quehacer teatral que pretendía motivar una renovación política y, sobre todo, estética. Todas estas discusiones apuntaban ciertamente a rearmar y crear un nuevo teatro frente a un contexto de doble crisis (estética y política), similar a lo que ocurría en el continente europeo.

En relación con lo anterior, encontramos aportes de Fukelman (2015) en los que vincula (estableciendo aproximaciones y diferencias) la propuesta de Barletta con aquella que describe Romain Rolland en su libro Teatro del Pueblo (publicado en francés en 1903), cuya primera traducción al español fue en 1927. En ambos casos, encontramos la necesidad de renovar la práctica teatral que diagnosticaban "en ruinas" a partir de una propuesta didáctica (enseñando al pueblo a reconocer el nuevo teatro que los salvaría de la crisis estética propagada por la oferta comercial). Un ejemplo de esto, lo encontramos en el siguiente fragmento: “¡En nombre del cielo, no demos al pueblo nuestras enfermedades, por mucha complacencia que hallemos cultivándolas entre nosotros! Tratemos de hacer una raza más sana y que valga más que nosotros" (Rolland, 1958, p. 37).

Así, Pelletieri (2006) asume que la clave del teatro independiente en Buenos Aires desde sus orígenes es hacer un "teatro para pensar" (p. 78). En este sentido, podemos preguntarnos hasta qué punto se trata de un Teatro del Pueblo o más bien un Teatro para el Pueblo, entendiendo la categoría pueblo desde un rol pasivo, como si fuera 
un niño que debe ser educado y salvado de la amenaza capitalista empresarial. El rol activo del encuentro artístico, entonces, quedaba en manos de los/as artistas profesionales e intelectuales que producían la obra (cuyo núcleo central estaba a cargo de quien ocupaba la dirección) $)^{5}$.

Resulta pertinente aclarar que, si bien se comprende al teatro independiente desde sus orígenes como un movimiento heterogéneo y rico en su diversidad, pueden pensarse algunos aspectos centrales que hacen a las identificaciones de los/as independientes. Una característica clave que menciona Fukelman (2017) en su tesis doctoral es que no todo trabajo teatral por cooperativa (como forma de optimizar recursos) es teatro independiente. Este último se comprende bajo una lógica de trabajo profesional (no aficionados/as) que no contempla a su práctica como un recurso para ganar dinero (Fukelman, 2016). De hecho, en relación con los modos de producción del teatro independiente encontramos que "los artistas pagan por su propio trabajo" (Fukelman, 2017, p. 301). De esta manera, el teatro independiente en sus orígenes se presenta como un trabajo profesional que no busca (y hasta incluso rechaza) la retribución económica. Esto es lo que autores/as como Mauro (2018a) denominan subjetividad autoprecarizante, en tanto que precariedad laboral se vuelve constitutiva de la actividad artística. Entonces, se elabora un producto que circula en el mercado, pero con fines opuestos al mismo. Así, entre los actores y las actrices de teatro independiente se desdibuja la noción de trabajadores/as, ocupando en su lugar, un rol militante, cuya misión es política, estética, intelectual y opuesta a la ganancia económica (Mauro, 2018b).

\section{Sobre los orígenes del teatro independiente en la ciudad de La Plata}

El caso de La Plata no dista mucho de lo que analizamos anteriormente. También algunos estudios como el de Di Sarli (2014) ubican a las primeras apariciones del teatro independiente en La Plata, ciudad capital de la Provincia de Buenos Aires (Argentina) en la década del ' 20 del siglo pasado. Para esa época, predominaban las obras extranjeras y empezaban a hacerse visibles autores/as nacionales. Mientras tanto, el Estado funcionaba como controlador doble: a nivel económico, atendiendo las demandas del público por el costo de entradas y horarios de funciones, y a nivel moral, observando el contenido de las distintas obras presentadas.

Un antecedente de lo que luego constituyó parte del movimiento de teatro independiente es la experiencia del Grupo Renovación. Radice y Di Sarli (2010) recuperan este grupo categorizando sus diferentes etapas: la conformación de Grupo Estudi-

5. Rancière (2010) desarrolla y argumenta una fuerte crítica a esta distinción de roles que concibe a los/as receptores/as de la obra como sujetos pasivos e inactivos. 
antil Renovación en 1920, el Teatro de Arte Renovación en 1926 y, finalmente, Teatro del Pueblo en 1933 (dos años después de la firma del acta fundacional del Teatro del Pueblo dirigido por Leónidas Barletta). En una primera instancia, el Grupo Renovación provino de la Universidad Nacional de La Plata (UNLP), institución oficial de legitimación cultural. Como observamos en una cita que Di Sarli (2014) hace de Benito Nazar Anchorena, presidente de la UNLP desde 1921, la propuesta intentaba hacer frente a la amenazadora propagación de géneros inferiores corrompiendo el buen gusto, particularmente por parte de las masas populares. Incluso antes de la traducción de Romain Rolland al español, aparecen algunas de sus ideas en el Grupo Renovación. Entre ellas encontramos la búsqueda de un buen teatro dirigido a las masas populares (comprendidas como entidades pasivas que se dejan llevar hacia el mal gusto artístico) con el fin de exorcizarlas de los efectos degradantes de teatro comercial de la época. En este sentido, el grupo fue buscando cierta innovación estética hasta conformar el Teatro del Pueblo en 1933, cuya función social se basaba en servir y estructurar al pueblo (Radice y Di Sarli, 2010, p. 96).

Para fines de la década del ‘50, la ciudad de La Plata ya contaba con al menos 30 grupos de teatro independiente. Según ha mencionado Gustavo Radice en un ciclo de charlas organizada por la Plataforma de Teatro Performático, después de la última Dictadura cívico-militar en Argentina (1976-1983), ocurre un nuevo auge del teatro independiente en La Plata. Entre algunas de las primeras experiencias que retoma Radice, encontramos el Taller de Investigación Dramática (TID) ${ }^{6}$ y el Grupo Teatral TESPIS ${ }^{7}$. Ambos casos fueron analizados a partir de las declaraciones registradas en el ciclo de charlas mencionado anteriormente, coordinado por Gustavo Radice y Carolina Donantuonni, con el fin de conocer la organización del teatro independiente en La Plata en los años de post-dictadura.

El TID fue un grupo similar al Teatro del Pueblo dirigido por Leónidas Barletta. En el caso de La Plata, el director que centralizaba todas las decisiones era Carlos Lagos a quien los actores y actrices que estudiaron y trabajaron con él, caracterizan como luminoso y oscuro a la vez. El primer calificativo lo explican por el compromiso político y estético de la propuesta en busca de conformar una vanguardia local. Aun así, decían que "había que bancarse estar ahí" por la dureza de la exigencia y la rigidez

6. La charla sobre la experiencia del TID con algunos de sus ex miembros. Recuperado de https:// plataformadeteatroperformatico.wordpress.com/2018/08/22/entrevista-publica-los-comienzosdel-teatro-independiente-platense-parte-i/.

7. La charla sobre la experiencia del Grupo teatral TESPIS con algunos de sus ex miembros. Recuperado de https://plataformadeteatroperformatico.wordpress.com/2019/05/16/grupo-teatraltespis-entre-la-estetica-teatral-y-la-politica-gremial/. 
de sus normas. Asimismo, notamos que entre quienes pertenecían a este grupo, se recuperaba la idea de que el espacio del TID "te salvaba de tener que entrar al mercado" en las mismas lógicas que lo planteaba el Teatro del Pueblo (alejándose de toda retribución económica o relación de dependencia directa a las instituciones privadas o estatales). Sin embargo, en ninguno de los casos llega a cumplirse completamente la independencia del mercado y las instituciones. Así como Leónidas Barletta quiebra ese pacto, por ejemplo, aceptando la oferta del Estado con salas para ensayos y funciones, Carlos Lagos cobraba honorarios por su trabajo8.

El Grupo teatral TESPIS se origina a partir del encuentro de experiencias militantes (principalmente barriales). A diferencia del TID, no se buscaban actores profesionales ${ }^{9}$, sino que el objetivo del grupo era expresarse políticamente a través del teatro. El grupo fundador surge de alumnos/as de otro espacio teatral de la época, el Taller de Teatro Rambla. Entre algunos eventos que recordaron, mencionaron unos ciclos de charlas en el club Universitario y las luchas que encabezaron por abrir los teatros oficiales y nuevas salas (ya que la mayor parte habían sido clausuradas por la última dictadura cívico-militar en nuestro país). Según relatan actores y actrices, el fin de este grupo se dio cuando el dueño del inmueble que alquilaban para usar como sala, donó sus propiedades a la Iglesia y se quedaron sin el espacio físico donde ensayar, reunirse y actuar.

Entonces, en La Plata también se reforzó desde los primeros años del siglo pasado hasta poco después de la dictadura militar en Argentina, una especie de asociación del teatro independiente como una actividad alejada de los principios mercantiles del sistema capitalista. Es decir, se comprendió al teatro como actividad de militancia política y/o cultural antes que como práctica laboral posible de garantizar la reproducción social.

\section{Trabajadores/as de la actuación en teatro independiente en La Plata}

Actualmente parece indiscutible que la práctica artística actoral es un trabajo. Teniendo en cuenta el marco normativo vigente en nuestro país, la actuación es un trabajo con regulaciones de contratación específicas respecto a otros empleos, tal como podemos ver en la Ley Nacional del Actor ( $\mathrm{n}^{\circ}$ 27.203). Esta ley se enfoca en la práctica laboral de actores y actrices que se encuentran trabajando en relación de dependencia y no de forma autónoma, es decir que no contempla al sector indepen-

8. Una diferencia que encontramos entre la propuesta de Lagos respecto a la de Barletta es que el primero pensó a sus miembros agrupados en una escuela, aunque esta nunca llegó a institucionalizarse.

9. El sentido de lo profesional se comprendía allí en la necesidad de formarse. Un ejemplo es que Carlos Lagos no permitía que los miembros del espacio de formación actuaran en público hasta no haber finalizado el ciclo de los tres años de escuela y presentado el proyecto final. 
diente. Sin embargo, este último queda incluido en la Ley de la Provincia de Buenos Aires $n^{\circ} 14037$. Allí, se comprende a la actividad teatral independiente de la siguiente manera: "Declárase de Interés Público a la actividad teatral independiente en la Provincia de Buenos Aires, como un trabajo cultural esencial para su desarrollo integral y como tal acreedora de la protección, promoción y apoyo del Estado" (ley n ${ }^{\circ} 14.037$, 2009, art. 1). En este sentido, se asume que la actuación en teatro independiente es un trabajo que debe ser protegido por el propio Estado.

Por otro lado, resulta pertinente destacar que en el artículo ${ }^{\circ} 12$ de la ley $n^{\circ} 27.203$, se asume y naturaliza el carácter discontinuo de la actividad actoral en general:

A los efectos de la seguridad social, los servicios de los trabajadores definidos en el artículo $1^{\circ}$ de la presente ley se califican como de carácter discontinuo y se regirán por lo dispuesto en el artículo 13.

Se entenderán por servicios discontinuos aquellos que, por las particularidades propias de la tarea, se prestan en forma alternada o intermitente durante todo el año calendario, con uno o varios empleadores (ley $\mathrm{n}^{\circ} 27.206$, 2015, art. 12).

Si bien se trata de una ley pensada para trabajadores/as contratados/as en relación de dependencia, creemos que aborda un aspecto clave para pensar al trabajo artístico en sí mismo. Es decir, se naturaliza como inestable a la tarea, asumiendo indiscutidamente su condición de trabajo incierto. Ahora bien ¿qué implica naturalizar el ejercicio actoral a un tipo de trabajo incierto?

El sociólogo francés Robert Castel (2012) caracteriza al individuo moderno a partir del concepto de incertidumbre, cuyo tipo ideal más óptimo para el sistema actual se presenta como individuo por exceso (p. 319). Es decir, un tipo de individuo "liberado/a" de la pesadez de los reglamentos y controles burocráticos, jurídicos, estatales. Pero en tanto individuo descolectivizado/a, se inserta en las nuevas lógicas relacionales a partir de un fuerte sentido de competencia. Esta exaltación del individuo en un contexto de competencia exacerbada que intenta liberar al sujeto de las cadenas de las regulaciones colectivas, supone individuos autosuficientes, independientes, competentes, capaces de tomar iniciativa, comprometidos/as y creativos/as (globalizados/as). Esas son las mismas condiciones que, según el texto de Legay (2003), caracterizan a los y las artistas. Menger (2009) afirma que el/la artista es el individuo por excelencia en tanto pretende destacar su talento individual en busca del éxito profesional. Por eso, la incertidumbre es, también, característica principal del trabajo artístico, ya que es la condición que se espera para asimilar oportunidades de éxito. Ahora bien, es necesario situar el problema para conocer y explicar cómo se percibe la incertidumbre laboral en el caso de la ciudad de La Plata. 
Resumiremos brevemente algunos aspectos centrales para conocer las condiciones materiales en que trabajan los actores y las actrices de teatro independiente que residen en La Plata. Para empezar, es necesario resaltar que existen distintos circuitos de producción donde los sujetos pueden desempeñar su actividad artística: el teatro comunitario ${ }^{10}$, entendido como un tipo de teatro barrial sustentado en la política de incluir a quien quiera participar en la actividad artística (sin importar género, edad, formación ni ninguna otra variable); el teatro comercial que se realiza por productoras o empresas privadas; el teatro oficial, cuya principal particularidad es que depende del financiamiento estatal y sus políticas de gestión; y finalmente el teatro independiente, que se entiende a partir de un tipo de producción autogestiva y es el que concentra la mayor producción teatral local.

En este último caso, son los/as mismos/as actores y actrices quienes se auto-convocan para llevar a cabo el producto artístico, organizados/as en grupos denominados elencos. Ellos/as trabajan por cooperativa, es decir, deciden entre todos/as cómo invertir el dinero que acumulan (a partir de lo que cada integrante pueda/quiera aportar), coordinan horarios de ensayos, materiales y recursos disponibles y realizan todo tipo de gestión administrativa que necesitan para llevar a cabo la obra. Los ingresos que suelen recibir son las entradas vendidas (restando el porcentaje acordado previamente que pagan por utilizar la sala), subsidios, premios y/o becas en caso de haber aplicado. En este sentido, se trata de una ganancia incierta, que no se evalúa ni diagnostica previamente y que muchas veces no alcanza a saldar todo lo invertido (o lo hace de manera escasa). En relación con lo anterior, Mauro (2018) advierte que esta modalidad autogestiva del teatro por cooperativa, desde sus inicios y en adelante, no se acopla a ningún aspecto de la Ley de Cooperativas y, de hecho, sostiene que los sujetos intervinientes en la misma se asemejan más a figuras militantes que trabajadores.

Lo que nos interesa analizar aquí, entonces, es la existencia de un imaginario imperante en el campo teatral porteño en el que la independencia ideológica y estética se entrelaza con una particular versión de cooperativismo que considera a la gratuidad como parte intrínseca del trabajo artístico (Mauro, 2018, p. 39).

10. Existen numerosos estudios sobre el teatro comunitario en Argentina, un ejemplo es el texto de Fernández (2013). 
Esta particular versión de cooperativismo se desentiende de las ganancias económicas como de aspectos relacionados a la seguridad social. De esta manera, no se proponen atender cuestiones relacionadas a aportes jubilatorios, obra social, entre otras, porque la gran mayoría trabaja en condiciones de no registro. Solamente, unos/ as pocos/as registran su trabajo a través de monotributo ${ }^{11}$.

Vale la pena aclarar que, para la elaboración de una obra de teatro, existen distintas tareas: actuación, dirección, dramaturgia, escenografía, iluminación, sonido, vestuario, maquillaje, fotografía, publicidad y gestión cultural. Sin embargo, los/as integrantes del elenco no siempre tienen roles definidos. Esto significa que muchas veces se reparten más de una tarea por integrante en la medida de las posibilidades de cada uno/a, es decir, según cómo puedan compatibilizar las actividades con otras responsabilidades personales (pueden ser otros trabajos, estudios, la crianza de niños/ as o personas mayores, entre otras).

Por lo general, los tiempos de producción de una obra de teatro en el circuito independiente son más extensos respecto las producciones comerciales y estatales. En primer lugar, porque al no tener ensayos pagos, muchas veces se dificulta la coordinación de horarios del total del grupo respecto a las distintas responsabilidades de todos/as los/as integrantes. Es clave entender que para la producción de una obra de teatro (a diferencia de otras obras de arte) los actores y las actrices son parte misma de la obra, su cuerpo integra el producto final (Basanta y del Mármol, 2020), por lo cual, las ausencias siempre afectan a la elaboración de aquello que se produce.

En relación con los espacios de trabajo, podemos determinar un número aproximado de cuántos teatros (al menos registrados) existen en la ciudad de La Plata. Según los archivos del Instituto Nacional del Teatro (INT), hasta octubre de 2018 se cuenta en la ciudad con 31 salas de teatro independiente registradas, 7 salas de teatros oficiales y 4 salas de teatro comerciales ${ }^{12}$. Lo que distingue (según la Ley $\mathrm{N}^{\circ} 14.037$, en el artículo 5, inciso A) a las salas independientes de las comerciales, es la cantidad de localidades: menos de 300 butacas es una sala independiente y, más de esa cantidad, es comercial. A su vez, las salas independientes y comerciales se diferencian de las oficiales a partir de su dependencia (siendo las últimas propiedad estatal y no privada).

11. Es una modalidad para registrar el trabajo de quienes ejercen de manera autónoma e independiente. Esto es regulado desde la Administración Federal de Ingresos Públicos (AFIP) en Argentina.

12. No mencionamos salas de teatro comunitario porque estos grupos no siempre tienen un espacio físico que les pertenezca. Sin embargo, cuando un grupo de teatro comunitario logra conformar una sala, ésta se registra como sala de teatro independiente (un ejemplo es La Caterva de City Bell). 
Es necesario destacar que los elencos no trabajan en salas fijas. Por lo general, tienen relaciones y afinidades con varias salas a la vez. Mientras algunos alquilan por hora una sala según conveniencia económica y geográfica, otros buscan lugares de ensayo distintos como plazas, centros culturales, instituciones educativas, clubes o sus propias casas.

De esta manera, se asume que las condiciones de trabajo de los/as artistas independientes se basan en lógicas de hiper-precariedad laboral (Menger, 2009), ya que se trabaja de manera fragmentada, mayoritariamente sin ningún tipo de registro ni regulación, con escasos o nulos ingresos, sin garantía de seguridad social, entre otras. Aun así, notamos que este circuito sigue produciendo más allá de la precariedad, por lo cual, es necesario comprender qué significados otorgan los sujetos a estas situaciones laborales.

\section{Sobre representaciones más recientes acerca del teatro independiente}

Consideramos que no pueden pensarse las problemáticas laborales desentendidas de las particularidades subjetivas que atraviesan a los sujetos. Siguiendo la perspectiva de Paugam (2012), es necesario no sólo saber cuáles son las condiciones de trabajo concretas para describirlas, sino que resulta eficaz atender también a los aspectos más subjetivos (en este sentido, se busca saber qué dicen los/as actores/actrices que hacen, por qué hacen lo que hacen y qué se observa que hacen). Por eso, en la encuesta realizamos una pregunta abierta que solicitaba a los/as encuestados/as, una definición de teatro independiente en pocas palabras. La gran mayoría de los resultados los ordenamos en la siguiente tabla: 
Tabla 1: Significado de teatro independiente según la perspectiva de actores y actrices en La Plata, 2018.

\begin{tabular}{|c|c|c|}
\hline Perspectiva Negativa & Perspectiva técnica & Perspectiva Positiva \\
\hline Odisea de lujo para pocos & Cooperativa-Experimental & $\begin{array}{c}\text { Espacio de encuentro } \\
\text { y aprendizaje, } \\
\text { trinchera social }\end{array}$ \\
\hline $\begin{array}{c}\text { Irregular, desparejo, } \\
\text { conservador, } \\
\text { automático, una posibilidad }\end{array}$ & $\begin{array}{c}\text { Espacio de } \\
\text { producción poético grupal }\end{array}$ & $\begin{array}{l}\text { Arte por fuera del } \\
\text { capitalismo }\end{array}$ \\
\hline $\begin{array}{l}\text { Remar en placentero dulce } \\
\text { de leche }\end{array}$ & $\begin{array}{c}\text { Circuito alternativo y } \\
\text { autogestivo de preponder- } \\
\text { ancia artística }\end{array}$ & $\begin{array}{l}\text { Arte, combativo y } \\
\text { transformador }\end{array}$ \\
\hline $\begin{array}{c}\text { Teatro hecho a pulmón / } \\
\text { Duro / Sacrificio }\end{array}$ & $\begin{array}{l}\text { Teatro Autogestivo de } \\
\text { investigación }\end{array}$ & $\begin{array}{c}\text { Encuentros para } \\
\text { decirnos algo }\end{array}$ \\
\hline $\begin{array}{c}\text { Circuito chico, grandes } \\
\text { artistas }\end{array}$ & $\begin{array}{l}\text { Convivencia y } \\
\text { entendimiento }\end{array}$ & $\begin{array}{c}\text { Sublimación- herramienta } \\
\text { de transformación- } \\
\text { puente- contrahegemónico }\end{array}$ \\
\hline $\begin{array}{l}\text { A pulmón / Mucho pulmón } \\
\text { / Autogestión a pulmón / } \\
\text { Tracción a sangre }\end{array}$ & $\begin{array}{c}\text { Trabajo artístico } \\
\text { sostenido por teatristas }\end{array}$ & Militancia \\
\hline $\begin{array}{c}\text { Con paciencia y saliva } \\
\text { garpas }\end{array}$ & $\begin{array}{l}\text { Autogestión, vocación, } \\
\text { creatividad, límites }\end{array}$ & \begin{tabular}{|cc} 
Pasión & esfuerzo lucha. \\
& Colectivo
\end{tabular} \\
\hline $\begin{array}{c}\text { Trabajo de estudio } \\
\text { laborioso }\end{array}$ & Autogestivo, colectivo & $\begin{array}{c}\text { Expresión integral de } \\
\text { ser politicx }\end{array}$ \\
\hline $\begin{array}{c}\text { Necesario, hippie, poco } \\
\text { ensayo }\end{array}$ & Trabajo colectivo & $\begin{array}{c}\text { Colectivo con ideales } \\
\text { marginales }\end{array}$ \\
\hline $\begin{array}{c}\text { Sacrificio, dedicación, } \\
\text { constancia, responsabilidad }\end{array}$ & $\begin{array}{l}\text { Actividad teatral no } \\
\text { financiada por ningún } \\
\text { organismo }\end{array}$ & $\begin{array}{l}\text { Modo de pensar/hacer } \\
\text { teatro popular }\end{array}$ \\
\hline $\begin{array}{c}\text { Privilegio clasemediero de } \\
\text { ciudades } \\
\text { pseudo-cosmopólitas }\end{array}$ & $\begin{array}{l}\text { Espacio de intercambio } \\
\text { cultural ad honorem }\end{array}$ & Lo más cercano a la libertad \\
\hline $\begin{array}{l}\text { Trabajo arduo no } \\
\text { reconocido }\end{array}$ & $\begin{array}{c}\text { Que se sostiene su propio } \\
\text { desarrollo }\end{array}$ & $\begin{array}{l}\text { Lo más de lo más / Una } \\
\text { actividad hermosa y difícil }\end{array}$ \\
\hline $\begin{array}{c}\text { Puro sacrificio y } \\
\text { organización constante }\end{array}$ & $\begin{array}{c}\text { No está obligado a generar } \\
\text { rentabilidad }\end{array}$ & $\begin{array}{l}\text { Teatro libre, crítico, } \\
\text { colectivo, autónomo }\end{array}$ \\
\hline $\begin{array}{c}\text { Autogestivo y de mucha } \\
\text { constancia }\end{array}$ & Crea tu trabajo & $\begin{array}{c}\text { Encuentro. Garra. Fuerza. } \\
\text { Autogestión }\end{array}$ \\
\hline
\end{tabular}

Fuente: Elaboración propia. 
Allí, observamos que existen distintos modos de caracterizar y representar al teatro independiente: por un lado, están quienes comprenden al circuito independiente desde una perspectiva positiva, entendiendo a lo independiente ensimismado del resto de los circuitos teatrales y destacando todas las atribuciones valorativas que lo engrandecen. Por otro lado, identificamos aquellas representaciones que lo ven desde un punto de vista más negativo, atribuyendo al término significados desesperanzadores. En el medio, ubicamos a quienes lo definen desde su organicidad técnica en tanto práctica autogestiva y sin retribución económica (esta interpretación se distancia de algunas de las definiciones teóricas de la bibliografía revisada sobre los orígenes del teatro independiente).

En relación con la perspectiva más positiva encontramos que existe cierta asociación en pensar al teatro independiente como una actividad libre, sin ningún tipo de atadura institucional.

Creo que el teatro independiente, por lo menos en el imaginario, es la libertad creativa que uno puede tener. Sin condicionamientos de ningún tipo. Hay algo de eso que hace que el teatro independiente sea muy atractivo por lo menos para el que lo hace. No sé si para los de afuera. Probablemente los de afuera odien el teatro independiente, pero uno de adentro siente mucha libertad porque no tiene ningún condicionamiento. Y para un artista no tener condicionamientos es importantísimo (Actor, 31 años).

Parece que el teatro independiente se asocia a una idea de creación artística sin importar cuál o cómo sea la recepción del público. Esto significa que la clave está en librarse de cualquier condicionamiento que pueda alterar los espacios de experimentación estética. Es decir, cuando los intereses son principalmente económicos, se asume que la exploración artística cobra un lugar secundario y se degrada el valor de la obra. Esto lo expresa una entrevistada de la siguiente forma:

(...) Es económicamente inviable el trabajo independiente en el sentido de que, como sus objetivos son básicamente artísticos el tiempo de exploración a veces se extiende y las personas siguen en un proyecto porque su interés mayor es justamente esa búsqueda artística. (...) Es muy antieconómico el funcionamiento de teatro independiente (Actriz, 29 años). 
En este sentido, entonces, aparece el siguiente problema: los actores y las actrices plantean al teatro independiente como un espacio de exploración artística, libre en términos estéticos como temáticos ${ }^{13}$, pero para poder hacerlo, deben tener resuelta su vida económica por otros medios. Es decir, se trata de aceptar esta lógica antieconómica y renunciar a la posibilidad de ganar dinero trabajando. Algo de esto incluso, presentan Basanta y del Marmol (2020) cuando mencionan que, en La Plata, el capital puesto en juego en el circuito de teatro independiente no es económico sino simbólico, en términos de reconocimiento y legitimidad dentro del sector. Por eso, cuando se presenta el interés artístico elevado a cualquier otro tipo de interés y preocupación, aparecen algunas tensiones.

(...) hay una tensión en mí, en otros teatristas ${ }^{14}$, donde se juega todo eso. El deseo de hacer arte, pero a su vez reconocer también que ese arte es un trabajo y que vivimos de eso. Y que hay toda una energía de trabajo que se despliega que también me interesa que tenga una remuneración económica. (...) hay cierto sentido social circulando de que como hacemos teatro no nos tiene que preocupar el dinero. No nos tiene que preocupar la remuneración. Que parecería ser que como hacemos algo que nos gusta mucho, ya está, esa sería nuestra paga (Actor, 43 años).

La paradoja presentada en este escrito se basa en las percepciones de precariedad laboral de los actores y actrices de La Plata frente a sus motivaciones del teatro independiente en tanto mundo económico al revés. Este último concepto sugiere que en el campo artístico existe una lógica antieconómica en la que el/la artista "sólo puede triunfar en el ámbito simbólico perdiendo en el ámbito económico" (Bourdieu, 2015, p. 130). Esto se ve literalmente atravesado por el principio de jerarquización autónoma, cuyo tipo ideal supone una autonomización absoluta respecto a las leyes del mercado. En este sentido, el reconocimiento depende de los y las semejantes, capaces de leer los códigos que dan a conocer su condición de artista (y validan la creencia de la misma). Esta idea aparece principalmente en el subcampo de producción restringida, cuya elaboración está destinada a lo/as mismos/as productores/as (un público capaz y habituado a leer los códigos estéticos) haciendo énfasis particular en la búsqueda del arte por el arte, es decir, arte puro e intelectual (Bourdieu, 2010). La conducta antieconómica, dice el autor, es el corazón de la actividad artística en sí. En este sentido, el arte puro es el arte por excelencia, mientras que el arte burgués es el arte no arte.

13. En varias entrevistas afirmaron que en teatro independiente circulan temáticas y problemáticas sociales concretas. Un ejemplo lo encontramos en la siguiente cita "(...) creo que el artista independiente tiene esa cuestión de libertad, que realmente podés hacer y decir lo que quieras, porque sos un artista independiente" (actor, 30 años).

14. Modo coloquial de llamar a las personas que trabajan en producciones teatrales. 
Esta perspectiva sostiene que la autonomía del campo artístico es relativa, aun así, observamos que la noción de mundo económico al revés es pertinente para pensar la paradoja planteada en el caso de actores y actrices de La Plata. La disputa subjetiva que habita el colectivo de actores y actrices de la ciudad se da por una doble representación afianzada en la localidad: por un lado, los significados valorativos que otorgan a la producción independiente en tanto espacio de legitimación cultural (Del Marmol, 2018) y por otro, el sentido de pertenencia al sector trabajador, fundamentado no solo en las representaciones de los sujetos sino también en el marco legal vigente.

A su vez, encontramos algunos casos que caracterizan al sector como "la cuna donde me críe" (actor, 27 años) o incluso "como esa cosa de hogar, de calidez. Como que, en general, vas a cualquier lugar de La Plata donde hagan teatro independiente y es un lugar cálido" (actriz, 27 años). Se vive como un hogar donde "siempre tenés la posibilidad de pertenecer" (actriz, 34 años). De hecho, pareciera ser que no solo se trata de un espacio de encuentro y convivencia, sino también de construcción colectiva:

(...) cuando uno tiene esa convicción, lo vas a seguir haciendo más allá de las situaciones adversas que te rodean. $Y$ en ese plano, el teatro independiente platense sigue sobreviviendo. (...) el teatro platense no lo fomenta ni el sindicato, ni cultura del municipio, ni la sala de la comedia, ni las universidades. Lo fomentamos los teatristas independientes. Sí, todas esas instituciones, está buenísimo que estén, podrían estar mucho más presentes, digo, pero (...) si pensamos que el teatro independiente desaparece porque nos cansamos todos y quedan nada más las instituciones, cagamos (Actriz, 34 años).

De esta manera, se deposita toda la confianza y la fe en la práctica de actores y actrices que trabajan y sostienen al teatro independiente. Por un lado, esto se da para cuidar ese espacio que contiene afectos y sentimientos colectivos y por otro, porque es el lugar donde actúa la gran mayoría que desea y puede practicar la actividad creativa.

El cooperativismo es un movimiento espléndido del teatro de autogestión (...) el tema es si ese va a ser tu único modo de producción. Te quieren convencer de eso, de que la única manera que tenés de trabajar es que te autoproduzcas, ¿entendés? Eso es (Actor, 42 años).

Entonces, observamos que, según los sujetos, el teatro independiente es el espacio donde ellos/as mismos/as logran contener la falta de trabajo de otros circuitos productivos. Incluso, mencionan que quienes desean hacer su trabajo actoral una fuente de ingreso mayor, deben ir a buscar trabajo a otro lado (particularmente en la Ciudad Autónoma de Buenos Aires, capital nacional de la Argentina). Por eso, sienten que la 
responsabilidad de generar trabajo y material artístico en la ciudad queda en ellos/as como sujetos políticos.

Parte de esta autonomía para resolver sus propias problemáticas laborales puede darse por ciertas condiciones legales, económicas y sociales que naturalizan la precariedad laboral de la actividad actoral. Además, estas condiciones se sostienen también, a partir de la legitimidad que otorgan actores y actrices al sector independiente en tanto circuito de producción libre de regulaciones (Del Marmol, 2018). Recuperando la cita de Flaubert del epígrafe, vale la pena preguntarnos si comprendemos a la actividad actoral como un derecho o como un lujo.

A diferencia de lo que encontramos en algunos estudios sobre una parte del movimiento de teatro independiente en sus orígenes y lo que algunos/as actores y actrices platenses recuerdan de la actividad del circuito independiente platense en el período post-dictadura, hoy en día la problemática por las condiciones de trabajo de los/as artistas cobra cada vez más fuerza en la discusión pública. Sin embargo, persisten fuertes valoraciones estéticas que resaltan el desinterés por la cuestión económica. Creemos que estas nociones contradictorias que conviven dentro de los significados que otorgan los/as artistas a su actividad, se explican, en parte, desde el concepto de mundo económico al revés (Bourdieu, 2015). No obstante, si solo consideramos este concepto dentro de las reglas del campo artístico local y actual, el circuito de teatro independiente quedaría reducido a un sector privilegiado que desea y encuentra la posibilidad de participar en el rubro, más allá de las condiciones materiales de producción (características que no parecen describir a sus miembros hoy en día).

En síntesis, sostenemos que la actividad artística necesita espacios de exploración y experimentación, ya que el arte no se comprende ni se explica desde la racionalidad ni argumentación lógica. Esa idea, permite entender el argumento por el cual, actores y actrices caracterizan al teatro independiente como algo necesario. Por eso, para finalizar recuperamos el deseo de los actores y las actrices de "poder vivir del teatro independiente" (actor, 27 años). La apuesta entonces, podría ser pensar nuevas formas de organizar la producción teatral local.

\section{Reflexiones finales}

En este trabajo hemos indagado las representaciones que tienen actores y actrices de teatro independiente sobre su actividad. Haciendo un recorrido histórico de algunas cuestiones planteadas desde las primeras décadas del siglo XX hasta los tiempos más recientes, observamos que el teatro independiente fue comprendido de distintas formas: por un lado, como respuesta al sector empresarial que practicaba como intermediario entre la compra y venta del producto artístico a costa de la explotación de los actores y las actrices (trabajadores/as que ponen su cuerpo como parte constitutiva de la obra de arte). Por otro lado, otros estudios también destacan la particularidad 
de la propuesta didáctica del teatro independiente frente a los peligros de la oferta comercial. En cualquiera de las dos ideas, encontramos que la actividad se comprende desde una subjetivación autoprecarizante (Mauro, 2018a). Por eso, algunos reclamos que ya protagonizaban las demandas del siglo pasado, hoy permanecen vigentes en el circuito. Considerando al teatro independiente comprendido en tanto mundo económico al revés (Bourdieu, 2015), podemos encontrar ciertos obstáculos que hacen al desarrollo y la propagación de la actividad, ya que, en un contexto de aumento de las incertidumbres (Castel, 2012), son cada vez menos quienes tienen la posibilidad de realizar actividades laborales en estas condiciones materiales basadas en la hiper-precariedad.

La paradoja presentada en este artículo funciona como eje para comprender representaciones convivientes y contradictorias sobre el teatro independiente. Estas contradicciones se estudian en base a los argumentos que sostienen con cada postura. De esta manera, encontramos que la perspectiva más negativa sobre lo independiente se explica a partir de condiciones materiales propias de un tipo de producción basado en la hiper-precariedad laboral (es decir, de ingresos nulos/ escasos, sin seguridad social, con inestabilidad laboral y con una gran demanda de tiempo y responsabilidad laboral). Mientras tanto, la perspectiva más positiva surge también desde la particularidad estética que constituye el arte independiente. En la motivación por no condicionar la práctica artística a meros cálculos económicos, muchos/as valoran el desentenderse de la cuestión económica buscando resolver eso por otros medios. En ese marco, los/as miembros de cada elenco se encuentran en pos de realizar una producción artística colectiva donde lo económico no sea un obstáculo. Lo interesante en este aspecto es atender a aquello que los sujetos plantean como problema: se desea seguir apoyando la propuesta estética arriesgada y experimental de buena parte del teatro independiente, mientras que también se espera que su trabajo sea reconocido social y económicamente.

En este artículo nos hemos concentrado en indagar de dónde surgen estas perspectivas y qué encontramos al poner a las distintas representaciones en diálogo. Por eso, nos permitimos desnaturalizarlas, analizando las distintas valoraciones que cobran en función a un contexto y una historia determinada. En consecuencia, resulta fundamental poner en práctica la imaginación sociológica (Mills, 2003) e indagar el problema más allá de lo dado. Sin caer en ningún tipo de reduccionismo, nuestra tarea es tratar de pensar a la actividad artística como un trabajo de exploración y experimentación (y por tanto que pueda asumir riesgos menos controlables que otras producciones) pero sin desconocer que existe a causa del esfuerzo físico y mental de trabajadores/as que lo producen. Para atender el problema planteado, conviene evitar resoluciones inmediatas desde una política pública aislada. En su lugar, este escrito invita a reflexionar el problema a partir de los sentidos y significados que se constru- 
yen sobre la actividad actoral. En síntesis, se trata de pensar nuevas formas de organización productiva posibles en el ámbito teatral platense. Esto implica atender a la experimentación artística mientras se escuchan las demandas laborales. Finalmente, proponemos desvincular al quehacer actoral de la noción de lujo, para concebirlo como la actividad de un sector inmerso en el mercado laboral actual.

\section{Referencias}

Baranger, Denis (2009). Construcción y análisis de datos. Posadas: Editorial Universitaria de Misiones.

Basanta, Leonardo y Mariana del Mármol (2020). El arte no paga. Reflexiones sobre el trabajo artístico en el contexto del capitalismo contemporáneo. Trabajo y Sociedad, XXI (35): 297-316. Recuperado de <https://www.unse.edu.ar/trabajoysociedad/35\%20AA\%20DEL\%20MARMOL\%20Y\%20BASANTA,\%20El\%20arte\%20 no\%20paga.pdf $>$.

Bourdieu, Pierre (2007). El sentido práctico. Buenos Aires: Siglo Veintiuno.

Bourdieu, Pierre (2010). El sentido social del gusto. Elementos para una sociología de la cultura. Buenos Aires: Siglo XXI.

Bourdieu, Pierre (2015). Las reglas del arte. Génesis y estructura del campo literario. Barcelona: ANAGRAMA.

Castel, Robert (2012). El ascenso de las incertidumbres. Trabajo, protecciones, estatuto del individuo. Buenos Aires: Fondo de Cultura Económica (FCE).

Castorina, José Antonio, Alicia Barreiro y Lorena Cerreño (2010). El concepto de polifasia cognitiva en el estudio del cambio conceptual. En M. Carretero y J. Castorina. La construcción del conocimiento histórico (pP. 131-152). Buenos Aires: Paidós.

Del Mármol, Mariana (2018). Hacer de la necesidad virtud. Ser teatrista independiente como modo de legitimación. En Revista Tempos e Espaços em Educação, 11 (24), 99-110. Recuperado de <https://www.researchgate.net/publication/322605812_ HACER_DE_LA_NECESIDAD_VIRTUD_SER_TEATRISTA_INDEPENDIENTE_COMO_MODO_DE_LEGITIMACION $>$.

Di Sarli, Natalia (2014). Historia del teatro en el período fundacional de La Plata (1890-1930): identidad urbana y proyecto artístico (Tesis de Maestría). Facultad de Bellas Artes. Recuperado de <http://hdl.handle.net/10915/36340>.

Fernández, Clarisa (2013). Antecedentes e historia del teatro comunitario argentino contemporáneo. Los inicios de un movimiento. En AISTHESIS, 54: 147-174. Recuperado de <https://scielo.conicyt.cl/scielo.php?script=sci_arttext\&pid$=$ S0718-71812013000200008>. 
Fukelman, María (2015). El vínculo entre Romain Rolland y Leónidas Barletta para el surgimiento del teatro independiente. En AdVersus, XII, 134-155. Recuperado de $<$ https://repositorio.uca.edu.ar/bitstream/123456789/5234/1/XII2907.pdf>.

Fukelman, María (2016). Aportes para la historia del teatro independiente de Buenos Aires. En Panambi, 2, 47-62. Recuperado de <https://revistas.uv.cl/index.php/ Panambi/article/view/534>.

Fukelman, María (2017). El concepto de "Teatro independiente" en Buenos Aires, del Teatro del Pueblo al presente teatral: estudio del período 1930-1946 (Tesis Doctoral) otorgada por la Facultad de Filosofía y Letras de la Universidad Nacional de Buenos Aires. Recuperado de <http://repositorio.filo.uba.ar/handle/filodigi$\operatorname{tal} / 4668>$.

Fukelman, María (2017a). Los antecedentes del teatro independiente en Buenos Aires: la importancia de Boedo y Florida. En Culturales, 1 (1): 151-187. Recuperado de $<$ http://www.scielo.org.mx/pdf/cultural/v5n1/2448-539X-cultural-5-01-00151. pdf $>$.

Fukelman, María (2017b). Capítulo III. Un recorrido por el Teatro del Pueblo, el primer teatro independiente de Buenos Aires. En Dubatti, J. (coord.) Teatro independiente. Historia y actualidad. Ciudad Autónoma de Buenos Aires: Ediciones del CCC Centro Cultural de la Cooperación Floreal Gorini.

Gonzalez Velasco, Carolina (2012). Gente de teatro. Buenos Aires: Siglo XXI.

Klein, Teodoro (1988). Una historia de luchas: la Asociación Argentina de Actores. Buenos. Aires. Ediciones AAA. Recuperado de <https://www.actores.org.ar/sites/ default/files/pdfs/historia\%20de\%20luchas.pdf >.

Legay, Marion (2003). Critique de Portrait de l'artiste en travailleur. Métamorphoses du capitalisme de P.M. Menger. Paris: Seuil.

Ley No27.203 (última vez visto: 07/2020). Recuperado de <https://bit.ly/2G52xEg >.

Ley $\mathrm{N}^{\circ} 14.037$ (última vez visto: 07/2020). Recuperado de <www.gba.gob.ar/cultura/ cpti>.

Longo, María Eugenia (2004). Los confines de la investigación social. Trabajo e identidades en jóvenes pobres. En IDICSO. Instituto de Investigación en Ciencias Sociales, 27, 1-29. Recuperado de <http://csoc.usal.edu.ar/archivos/csoc/docs/idicso-sdti027.pdf>.

López-Roldán, Pedro y Sandra Fachelli (2015). Capítulo II. La encuesta. En P. LópezRoldán y S. Fachelli, Metodología de la Investigación Social Cuantitativa. Bellaterra (Cerdanyola del Vallès): Dipòsit Digital de Documents, Universitat Autònoma de Barcelona. Recuperado de <http://ddd.uab.cat/record/163567>. 
Mauro, Karina (2018). Cooperativismo y condiciones laborales de los actores en el teatro porteño. En Revista Pilquen, 21(5): 38-48. Recuperado de <https://dialnet. unirioja.es/servlet/articulo?codigo $=6775667>$.

Mauro, Karina (2018a). Entre el mundo del arte y el mundo del trabajo. Herramientas conceptuales para comprender la dimensión laboral del trabajo artístico. En Telóndefondo, 27, 114-123. Recuperado de <http://revistascientificas.filo.uba.ar/ index.php/telondefondo/article/view/5097>.

Mauro, Karina (2018b). Identidades y apelaciones antagónicas de los trabajadores del espectáculo (1902-1955). En Telóndefondo, 27, 176-231. Recuperado de <http:// revistascientificas.filo.uba.ar/index.php/telondefondo/article/view/5100>.

Menger, Pierre-Michel (2009). L'art analysé comme un travail. Idées économiques et sociales, 4 (158): 23-29. Recuperado de <https://www.cairn.info/revue-ideeseconomiques-et-sociales-2009-4-page-23.htm>.

Mills, Charles Wright (2003). Capítulo I. La promesa. En Mills, C. W. (2003). La imaginación sociológica. México: FCE. Recuperado de https://www.cba.gov.ar/ wp-content/4p96humuzp/2016/04/Wright-Mills-La-Promesa-Pag-23-43.pdf.

Paugam, Serge (2012). Protección y reconocimiento. Por una sociología de los vínculos sociales. En Papeles de CEIC, 82, 1 - 19. Recuperado de < https://www.redalyc. org/articulo.oa?id=76524825001>.

Pelletieri, Osvaldo (2006). Capítulo III. Algunos aspectos del 'teatro de arte' en Buenos Aires (1930-1975). En O. Pelletieri. Teatro del Pueblo: Una utopía concretada. Buenos Aires: Galerna.

Radice, Gustavo y Natalia Di Sarli (2010). Historia de la modernización del lenguaje teatral en La Plata (1900-1982). En Boletín de Arte del Instituto de Historia del Arte Argentino y Americano, Facultad de Bellas Artes, Universidad Nacional de La Plata, 11, (12): 93-106. Recuperado de <http://sedici.unlp.edu.ar/handle/10915/18594>.

Rancière, Jacques (2010). El espectador emancipado. Buenos Aires: Manantial.

Rolland, Romain (1958). Teatro Completo I. Buenos Aires: Hachette. 


\section{Sobre la autora:}

Juliana Díaz es Licenciada y Profesora en Sociología por la Facultad De Humanidades y Ciencias de la Educación de la Universidad Nacional de La Plata (FaHCE-UNLP). Doctoranda en Ciencias Sociales (FaHCE-UNLP). Becaria doctoral en el Consejo Nacional de Investigaciones Científicas y Técnicas de Argentina (CONICET). Miembro del Laboratorio de Estudios en Sociología y Economía del Trabajo del Instituto de Investigaciones en Humanidades y Ciencias Sociales (LESET-IdIHCS/ CONICETUNLP). Tema de investigación: Sociología del trabajo artístico en teatro. La Plata, Buenos Aires, Argentina. Correo Electrónico: julianadiaz345@gmail.com. (Dttps:// orcid.org/0000-0002-5922-2930 


\title{
CUHSO
}

Fundada en 1984, la revista CUHSO es una de las publicaciones periódicas más antiguas en ciencias sociales y humanidades del sur de Chile. Con una periodicidad semestral, recibe todo el año trabajos inéditos de las distintas disciplinas de las ciencias sociales y las humanidades especializadas en el estudio y comprensión de la diversidad sociocultural, especialmente de las sociedades latinoamericanas y sus tensiones producto de la herencia colonial, la modernidad y la globalización. En este sentido, la revista valora tanto el rigor como la pluralidad teórica, epistemológica y metodológica de los trabajos.

\author{
EDITOR \\ Matthias Gloël \\ COORDINADORA EDITORIAL \\ Claudia Campos Letelier \\ CORRECTOR DE ESTILO Y DISEÑAdOR \\ Ediciones Silsag \\ TRADUCTOR, CORRECTOR LENGUA INGLESA \\ Aurora Sambolin Santiago \\ SITIO WEB \\ cuhso.uct.cl \\ E-MAIL \\ cuhso@uct.cl \\ LICENCIA DE ESTE ARTÍCULO \\ Creative Commons Atribución Compartir Igual 4.0 Internacional
}

